\title{
Análise imunohistoquímica de glândulas salivares menores e de fígado após o transplante alogênico de medula óssea
}

\author{
Susan M. O. Choi (IC), Tânia C. B. Soares (PQ), Maria L. Cintra (PQ), Maria E. P. Correa (PQ)
}

\section{Resumo}

GVHD crônico é uma complicação grave do transplante alogênico de medula óssea (TMO), sendo glândulas salivares e fígado dentre os mais acometidos. O objetivo do trabalho é correlacionar achados imunohistoquímicos de pacientes com acometimento hepático e com acometimento de glândula salivar menor por GVHD pós TMO alogênico.

Palavras Chave: GVHD, fígado, glandulas salivares menores.

\section{Introdução}

A doença do enxerto contra hospedeiro crônica (DECHc) após o transplante de medula óssea (TMO) alogênico é uma desordem auto e aloimune, multissistêmica caracterizada por desregulação imunológica, imunodeficiência e perda de função. Linfócitos $\mathrm{T}$ alógenos reconhecem os antígenos $\mathrm{MHC}$ do receptor como exógenos, levando a expansão clonal e finalmente à $\mathrm{DECHc}^{1,2}$. Os órgãos mais afetados são pele, mucosa oral, glândulas salivares e fígado ${ }^{3}$. O epitélio dos ductos biliares menores intra-hepáticos é comumente lesionado, semelhantemente à glândula salivar e aos ductos lacrimais, que contem alta densidade de antígenos $\mathrm{MHC}{ }^{4,5}$. O objetivo do trabalho foi correlacionar achados imunohistoquímicos (CD4, CD8, CD45, CD68 e CD138) de pacientes com acometimento hepático e de glândula salivar menor (GSM) por DECHc pós TMO alogênico.

\section{Resultados e Discussão}

Biópsias de fígado e GSM de 36 pacientes tratados por TMO alogênico aparetado HLAcompatível foram analisadas. O material examinado foi submetido à técnica de imunohistoquímica para marcação das células com expressão de CD4, CD8, CD45, CD68 e CD138. A partir das lâminas coradas, foram capturadas imagens digitais para a quantificação das células imuno-marcadas.

Houve correlação entre o número de células $/ \mathrm{mm}^{2}$ imuno-marcadas em GSM e fígado para as seguintes populações: CD4(82\%, p<0,001), CD8 $(61 \%, p=0,002)$, CD45 (46\%, $p=0,01)$ e não houve correlação significativa para os marcadores CD68, CD138.

\section{Conclusões}

O infiltrado mononuclear em GSM reflete aquele observado no fígado. Considerando os achados clínicos e laboratórios, biópsias de GSM, que são obtidas facilmente, poderiam ser usadas para estimar alterações hepáticas em pacientes com GVHD crônico.

\section{Agradecimentos}

Ao Departamento de Anatomia Patológica FCM/UNICAMP, ao departamento de Transplante de Medula Óssea - Hemocentro/UNICAMP, ao Pibic/SAE e Fapesp.

\footnotetext{
${ }^{1}$ Welniak LA, Blazar BR, Murphy WJ. Immunobiology of allogeneic hematopoietic stem cell transplantation. Annu Rev Immunol 2007;25:139-70.

${ }^{2}$ Fraser CJ, Bhatia S, Ness K, Carter A, Francisco L, Arora M, Parker P, Forman S, Weisdorf D, Gurney JG, Baker KS. Impact of chronic graft-versus-host disease on the health status of hematopoietic cell transplantation survivors: a report from the Bone Marrow Transplant Survivor Study. Blood. 2006;108(8):2867-73

${ }^{3}$ Ferrara JL, Levine JE, Reddy P, Holler E. Graft-versus-host disease. Lancet. 2009;373(9674):1550-61

${ }^{4}$ Soares AB, Faria PR, Magna LA, Correa ME, Sousa CA, Almeida OP, Cintra ML. Chronic GVHD in minor salivary glands and oral mucosa: histopathological and immunohistochemical evaluation of 25 patients. J Oral Pathol Med 2005;34(6):368-73.

${ }^{5}$ Quaglia A, Duarte R, Patch D, Ngianga-Bakwin K \& Dhillon A P. Histopathology of graft versus host disease of the liver. Histopathology 2007;50:727-738.
} 